
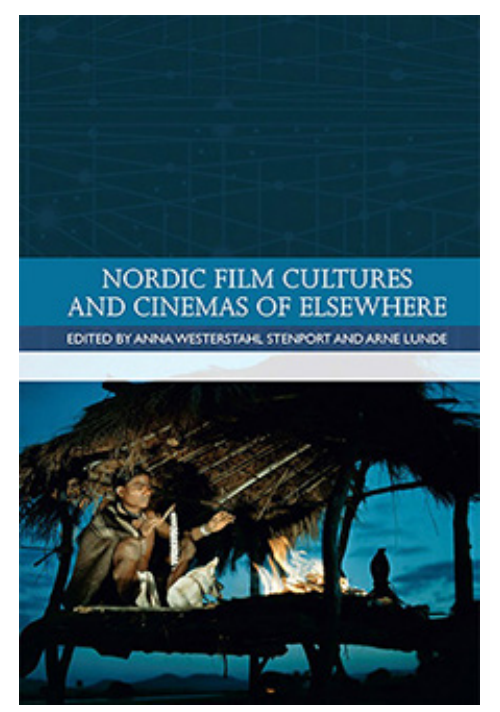

LAAJASTI POHJOISMAISEN ELOKUVAKULTTUURIN KANSAINVÄLISIST $\ddot{A}$ YHTEYKSIST $̈$

Anna Westerstahl Stenport \& Arne Lunde (toim.) (2019) Nordic Film Cultures and Cinemas of Elsewhere. Edinburgh: Edinburgh University Press, 389 s.
Nordic Film Cultures and Cinemas of Elsewhere -teoksen tekijät haluavat laajentaa pohjoismaisen elokuvan tutkimusta kansallisen kontekstin ulkopuolelle. Kirjan luvuissa tarkastellaan monista eri lähtökohdista käsin pohjoismaisen elokuvakulttuurin toimintaa ja vaikutusta kansallisten rajojen ulkopuolella historian eri vaiheissa.

Kyse on siis monenlaisten ylirajaisten suhteiden, yhteistyön muotojen ja vaikutteiden tarkastelemisesta, vaikka termiä transnationaali ei ole nostettu otsikkoon. Hieman kankeasti suomeksi kääntyvällä termillä cinemas of elsewhere tarkoitetaan toisaalle sijoittuvia elokuvakulttuureita. Tekijöiden mukaan kaikki elokuvakulttuurit, myös pohjoismaiset, ovat toisaalla olevia silloin kun niitä tarkastellaan jonkun toisen kulttuurin näkökulmasta. "Toisaalla" ei siis tarkoita mitään tiettyä paikkaa tai aluetta, vaan se määrittyy tarkastelijan position mukaisesti. Termi ymmärretään kirjassa myös metaforisesti, elokuvan rakentamina kuvitteellisina paikkoina ja ilmiöinä, kuten 1950-luvun suurelokuvien eksoottisena Lappina tai Yhdysvalloissa elokuvan Olen utelias - keltainen (Jag är nyfiken - en film i gult, Ruotsi 1967) synnyttämänä mielikuvana Ruotsista seksuaalisesti vapaamielisenä maana.

Hieman yllättäen käsitteen valintaa ei perustella johdannossa eikä kirjaan sisältyvää tutkimusta suhteuteta sen kummemmin transnationaali-käsitteen alla pohjoismaisesta elokuvasta aiemmin tehtyyn tutkimukseen. Kummalliselta tämä tuntuu erityisesti siksi, että johdannossa kuitenkin luetellaan pitkä lista transnationaalin ideaa hyödyntäviä pohjoismaista elokuvaa käsitteleviä teoksia. Otsikko tuntuu tekijöiden aikomuksista huolimatta korostavan me-he-polariteettia ja viittaavan toisaalla olevaan jotenkin eksoottisena, mitä vahvistaa kansikuvavalinta, otos Arne Sucksdorffin Intiaan sijoittuvasta dokumenttielokuvasta The Flute and the Arrow (1957).

Toimittajien Anna Westerstahl Stenportin ja Arne Lunden mukaan artikkeleissa kartoitetaan vähälle huomiolle tai täysin ilman huomiota jääneitä ilmiöitä ja lähestytään kanonisoituja tutkimuksen kohteita uudenlaisista näkökulmista tai lukemalla niitä vastakarvaan. Ajallisesti tarkasteltava ajanjakso ulottuu mykkäelokuvasta nykypäivään. Aiemmassa tutkimuksessa paljon huomiota saaneina aiheina toimittajat mainitsevat muun muassa Tanskan ja Ruotsin mykkäelokuvan kulta-ajan 1910-20-luvut, ruotsalaisen 1950-60-lukujen taide-elokuvan, yksittäiset auteurit sekä tanskalaisen Dogma 95 -liikkeen. Näitä ilmiöitä ei sivuuteta täysin tässäkään teoksessa, mutta näkökulmat niihin ovat tuoreita. Esimerkiksi Annie Fee tarkastelee artikkelissaan "Paris looks to the North: Swedish Silent Film and the Emergence of Cinephilia" kuinka ruotsalaiset kulttuurin lähettiläät ja kulttuurialan yrittäjät synnyttivät käsitteen ruotsalainen taideelokuva ja samalla vaikuttivat ranskalaisen elokuvaentusiasmin syntyyn 1920-luvun Pariisissa. Myös Linda Badleyn artikkeli Lars von Trierin ja Thomas Vinterbergin luomista kuvitteellisista amerikoista, joissa elokuvan(kin) supervaltaa tarkastellaan "toisaalta" käsin ja 
amerikkalaisen elokuvan omia stereotyyppejä hyödyntäen, on piristävällä tavalla uudenlaisen tarkastelutavan tarjoava teksti.

Teoksen rakenne ei ole kronologinen, mutta käsiteltävät ilmiöt asetetaan historialliseen kontekstiinsa johdantoluvussa. Tämä on hyvä ratkaisu, sillä 29 luvusta koostuva teos on melko vaikeasti hahmotettava kokonaisuus. Teos on jaettu neljään temaattiseen osaan, joiden otsikot eivät ole kovin informatiivisia: Traces and Erasures, Intermediaries, Contact Zones ja Revisitations. Ensimmäisessä osassa käsitellään huonosti tunnettuja, historian kätköihin unohtuneita tarinoita, medioita ja henkilöitä, kuten pohjoismaisen mykkäelokuvan vientiä Australiaan ja Amerikassa vaikuttaneen ruotsalaisnäyttelijä Warner Olandin tapausta. Toisen osan artikkelit käsittelevät kulttuurisia välittäjähahmoja, kuten saamelaisen Nils Gaupin kansainvälistä uraa sekä Aki Kaurismäen kytköksiä Ranskaan. Ana Benito Ribeiro tarkastelee lyhyessä luvussaan Kaurismäen Ranskaan sijoittuvia ja osittain ranskalaista tuotantoa olevia elokuvia, kuten Boheemielämää (1992) ja Le Havre (2011), ja luonnehtii yleisesti Kaurismäen elokuvien todellisuutta "toisaalle", ei tarkalleen ottaen mihinkään, sijoittuvaksi.

Kolmannessa, Mary Louise Prattin käsitteen contact zone mukaisesti nimetyssä, osassa tarkastellaan eri sijaintien välisiä kosketuspintoja ja kohtaamisia. Tässä osassa on kirjan toinen suomalaista elokuvaa käsittelevä luku, Anneli Lehtisalon lyhyt, mutta uutta tietoa tarjoava teksti suomalaisen elokuvan viennistä ja vastaanotosta Amerikan suomalaissiirtolaisten keskuudessa suomalaisen elokuvan studiokaudella 1938-1941. Troy Storfjell käsittelee alkuperäiskulttuurien välisten tilojen rakentumista Elle-Máijá Apiniskim Tailfeathersin lyhytelokuvassa Bihttoš (Kanada ja Norja, 2014), joka pureutuu elokuvantekijän perheen kolonialismin sävyttämään historiaan. Ohjaajan isä oli saamelainen ja äiti mustajalkaintiaani.

Neljännessä osassa ajatuksena on tunnettujen tekijöiden elokuvien uudelleentarkastelu ja pohdinta siitä, miten niitä on uudelleenversioitu tai miten niiden vastaanotto on muuttunut kontekstista riippuen. Casper Tybjerg esimerkiksi käsittelee Carl Dreyerin Jeanne D'Arcin kärsimys (La Passion de Jeanne d'Arc, 1928 Ranska) -elokuvasta 1950-luvulla tehtyä kiistanalaista uutta versiota. Anne Westerstahl Stenport ja Arne Lunde puolestaan kirjoittavat Ingmar Bergmanin 1970-luvun Berliinissä omaehtoisen maanpakonsa aikana ohjaamasta Käärmeenpesästä (The Serpent's Egg, 1977 USA ja Länsi-Saksa), joka kaivautuu Weimarin ja natsi-Saksan historiaan. He analysoivat elokuvan tyyliä 1970-luvun uuden saksalaisen elokuvan ja uuden Hollywoodin risteymänä ja Bergmanin kaikkein vähiten skandinaavisena projektina.

Temaattisista osioista huolimatta luvut jäävät irrallisen oloisiksi. Monet niistä eivät liity toisiin lukuihin muuten kuin hyvin yleisellä tasolla, sillä "toisaalla" ymmärretään hyvin laajasti. Kirjan sisältö on tästä johtuen myös erittäin moninainen, samoin kuin artikkeleiden käsittelytavat. Kirjan toisen osan sisällä esimerkiksi hypätään Ingrid Bergmanin "diasporisista" elokuvista sodanjälkeisten tanskalaisten opetuselokuvien ääniraitojen tarkasteluun. Painotus on historiallisessa tarkastelussa ja ilmiöiden kuvaamisessa, ei niinkään tulkinnassa tai teoreettisessa analyysissä. Tutkimuskohteisiin lukeutuu yksittäisiä elokuvia ja elokuvanäyttelijöitä, yksittäisen tekijän tuotanto kokonaisuudessaan, elokuvia eri maista yhteisen teeman alla tarkasteltuna, elokuvien vienti ja esitystoiminta. Fiktioelokuvien ohella tarkastellaan dokumenttielokuvia, musiikkivideoita, opetuselokuvia ja televisiosarjoja. Punaiseksi langaksi voi hahmottaa suhteisuuden ja vuorovaikutuksen, uudenlaisen perspektiivin ottamisen ja historian hämärään unohtuneiden ilmiöiden huomioimisen.

Teoksessa painottuu vahvasti ruotsalainen elokuvakulttuuri, mikä ei ole yllätys ottaen huomioon, että ruotsalaisen elokuvatuotannon volyymi on kautta historian ollut Pohjoismaiden suurin. Noin puolet luvuista käsittelee ruotsalaista elokuvaa tai elokuvakulttuuria. Tanskalaista elokuvakulttuuria käsitellään seitsemässä luvussa, suomalaista ja norjalaista molempia kahdessa. Islantilainen elokuva loistaa poissaolollaan, mikä on häiritsevää, kun ottaa huomioon Islannin roolin esimerkiksi nordic noir -ilmiössä ja ohjaaja Baltasar Kormákurin kansainvälisen uran. Saamelaista elokuvaa sen sijaan käsitellään ilahduttavasti kahdessa luvussa. Lisäksi Westerstahl-Stenport tutkii Saamenmaalle sijoitettuja elokuvia osana 
1950-luvun eksoottisia spektaakkelielokuvia, joiden kautta pohjoismaiset elokuvatekijät tavoittelivat kansainvälistä huomiota. Tässä luvussa mainitaan lyhyesti myös Valkoinen peura (1952, Suomi). Suomalaisen nykyelokuvan kansainvälisesti tunnetuin ja siten myös "toisaalla"-teeman näkökulmasta merkityksellisin hahmo näyttää edelleen olevan Aki Kaurismäki. Harmi, ettei esimerkiksi korkeatasoisesta suomalaisesta dokumenttielokuvasta ole löytynyt kirjaan kirjoittajaa.

Vaikka aiheiden kirjo ja ajallinen kaari ovat laajoja, joitakin olennaisia teemoja teoksesta on jäänyt pois. Esimerkiksi maahanmuuttajien tekemää elokuvaa ei käsitellä ollenkaan, vaikka etenkin Ruotsissa ja Norjassa maahanmuuttajia on toiminut elokuva-alalla jo muutaman vuosikymmenen ajan. Tämän erittäin valitettavan puutteen tekijät mainitsevat itsekin listatessaan kirjan ulkopuolelle jääneitä aiheita. Itseäni ilahdutti erityisesti se, että kirjassa tuodaan esiin Pohjoismaiden osallisuutta kolonialismiin ja erilaisten toiseuksien rakentamiseen.

Aiheiden moninaisuuden ja hieman vaikeasti hahmotettavan rakenteensa vuoksi on epätodennäköistä, että kovin moni lukija innostuisi kahlaamaan koko teoksen läpi. Yhtenäisen lukukokemuksen sijasta kirja tarjoaa pikemminkin kiinnostavia tärppejä pohjoismaisesta elokuvasta kiinnostuneelle lukijalle. Yksittäiset tekstit ovat hyvin kirjoitettuja, huolelliseen tutkimukseen perustuvia ja siten miellyttäviä lukukokemuksia.

\section{Kaisa Hiltunen}

FT, taidekasvatus, Jyväskylän yliopisto 